\title{
Utilização da Coluna de Winogradsky para a Demonstração do Efeito dos Metais Pesados na Microbiota Oxidante de Enxofre em Ambientes Aquáticos: Uma Abordagem Experimental
}

\section{Using Winogradsky Column to the Demonstration of the Effect of Heavy Metals in Sulfur Oxidizing Microorganism in Aquatic Environments: an Experimental Approach}

\author{
Anderson Gomes ${ }^{1}$ \\ Lara dos Santos Osório²
}

Palavras-chave:

Microbiologia

Coluna de winogradsky

Metais pesados

\section{Resumo}

O presente estudo teve por objetivo determinar o efeito dos metais pesados: mercúrio, cádmio, chumbo e cromo VI, na população de sulfobactérias presentes em colunas de Winogradsky. As colunas foram preparadas com água e sedimento do córrego Secades (Volta Redonda/RJ), para avaliar a contribuição potencial na disponibilidade destes metais pesados nesta população microbiana. Na avaliação do efeito dos metais pesados na população de sulfobactérias, foi comparada a diversidade das colônias desenvolvidas nas colunas contaminadas com metais pesados com uma coluna contendo apenas amostra e sedimento do manancial. Os resultados permitiram observar que a presença dos diferentes metais pesados causou alteração da diversidade biológica presente na coluna de Winogradsky. O estudo também revelou que o experimento pode ser aplicado nas aulas práticas de Microbiologia Ambiental, pois permite simular as condições reais da interação das sulfobactérias com os metais pesados.
Abstract

The present study aimed to determine the effect of the heavy metals: mercury, cadmium, lead and chrome VI, in the population of present sulforbacteria in columns of Winogradsky. The columns were prepared with water and sediment of the stream Secades (Volta Redonda/RJ), to evaluate the potential contribution in the availability of these heavy metals in this microbial population. In the evaluation of the effect of the heavy metals in the sulforbacteria population, the diversity of the colonies developed in the contaminated columns with heavy metals was compared to a column containing just a sample and the stream sediment. The results allowed to observe that the presence of different heavy metals caused alteration of the present biological diversity in the column of Winogradsky. The study also revealed that the experiment can be applied in the practical classes of Environmental Microbiology, because it allows to simulate the real conditions of the interaction of the sulforbacteria with the heavy metals.
Key words:

Microbiology

Winogradsky

column

Heavy metals

\section{Artigo \\ Original}

Original

Paper

Recebido em 05/2011

Aprovado em $08 / 2011$

\footnotetext{
${ }^{1}$ Mestrando, Biólogo, Especialista em Microbiologia, Docente dos Cursos de Ciências Biológicas e Engenharia Ambiental do Centro Universitário de Volta Redonda - UniFOA

${ }^{2}$ Técnica em Química - Centro Integrado de Tecnologia - CIT - Centro Universitário de Volta Redonda - UniFOA.
} 


\section{Introdução}

Com o desenvolvimento das atividades industriais, ocorreu a introdução de metais pesados nos corpos hídricos, numa quantidade muito maior do que ocorre naturalmente, o que vem causando grandes poluições hídricas. Essas poluições são causadas principalmente pela ausência de tratamento dos efluentes industriais ou por acidentes que levam o despejo de muitos poluentes nos ambientes aquáticos.

Dos grupos de poluentes gerados nos processos industriais, podem se destacar os metais pesados, que são um grande problema para o meio ambiente, pois estes afetam a microbiota dos corpos hídricos que recebem estes poluentes. Os principais problemas que os metais pesados causam na microbiota são a bioacumulação (processo através do qual os seres vivos absorvem e retêm substâncias químicas no seu organismo) nos microrganismos na base da cadeia trófica, e a inibição do crescimento ou morte de algumas espécies microbianas mais sensíveis.

A importância de conhecer o efeito da ação de metais pesados aos microrganismos presentes em ambientes aquáticos nas condições próximas daquelas existentes na natureza é de vital importância no ensino da Microbiologia no curso de Engenharia Ambiental, em contraste ao estudo dos microrganismos em condições in vitro. Isso se dá devido à diversidade de espécies microbianas envolvidas na ciclagem de nutrientes num ecossistema. Por este motivo é necessário um instrumento apropriado para a demonstração dessas condições em ambientes naturais. A coluna de Winogradsky é um modelo interessante que simula as condições de ecossistemas naturais, na qual desenvolve de populações bacterianas fotossintéticas que utilizam o sulfeto de hidrogênio como doador de elétrons durante o metabolismo fotoautotrófico, onde é possível observar as sucessões microbianas em um ambiente aquático, uma vez que as microbiota presente se modificam ao longo do tempo e sob a ação dos fatores ecológicos que atuam nesta comunidade.

\subsection{A coluna de Winogradsky}

A coluna de Winogradsky foi um sistema criado pelo microbiologista russo Sergei Winogradsky, no ano de 1880 para estudar microrganismos presentes no solo. Até hoje é utilizado como um sistema que permite demonstrar, de uma maneira bastante simples, a diversidade microbiana em ambientes aquáticos.

Tradicionalmente, o modo de desenvolver este sistema é feito colocando lama do fundo de um lago ou rio em uma coluna de vidro ou outro material transparente, complementado com uma fonte de celulose, seja na forma de carboximetilcelulose (CMC) ou através de papel picado, suplementado com uma fonte de sulfatos e uma solução tamponante (para manter o pH estável). Essa coluna então é tampada com uma tela fina (para evitar proliferação de mosquitos) e colocada em um local onde receba luz solar. Com o passar dos dias irão se desenvolver colônias de microrganismos estratificados ao longo da coluna, de acordo sua estratégia metabólica (aeróbios mais na superfície, anaeróbios no fundo, microaerófilos numa faixa estreita da coluna e facultativos ao longo da coluna). Conforme demonstrado na figura 1. 


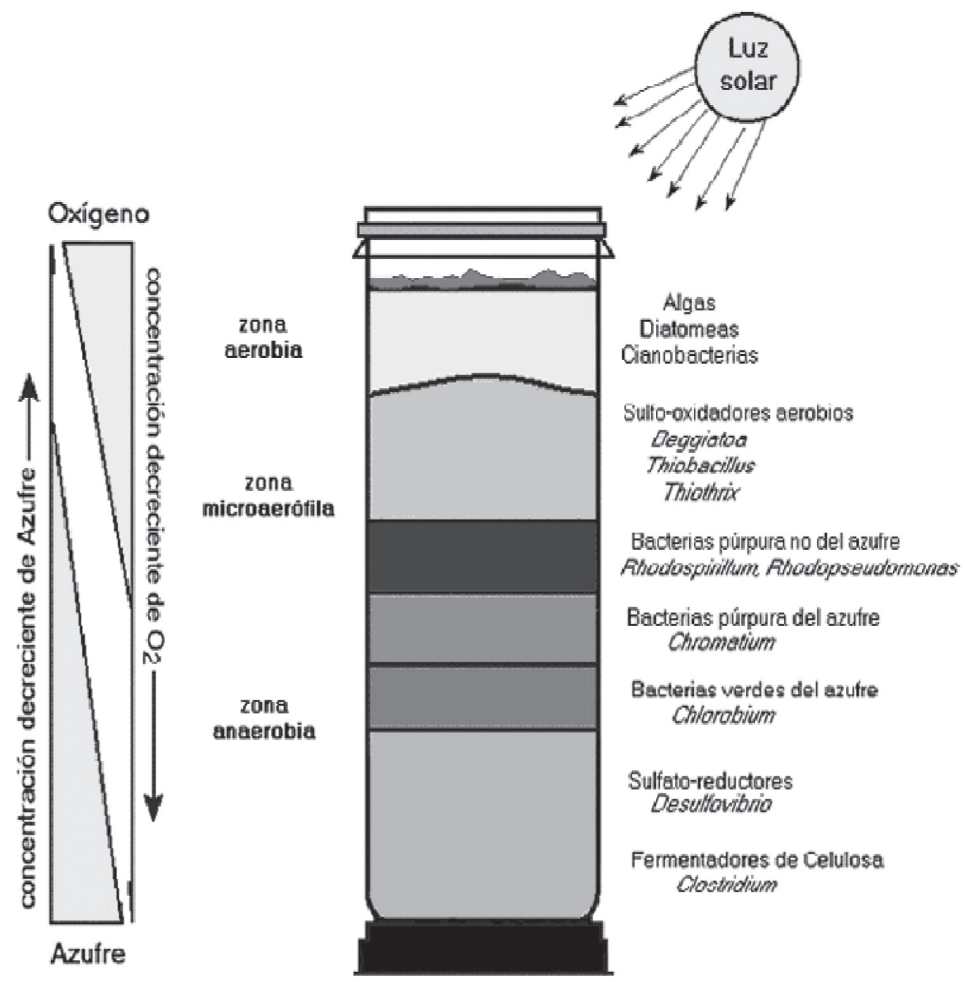

Figura 1 - Desenvolvimento de comunidade microbiana em coluna de Winogradsky, disponível em http://www.qb.fcen.uba.ar/microinmuno/SeminarioBiodiversidad.htm, consultado em 24/04/2011.

\subsection{Estratificação das sulfobactérias ao longo da coluna d'água}

Grant (1989) cita que a distribuição das bactérias oxidantes de enxofre, ao longo de uma coluna d'água, é relacionada com a concentração de sulfetos e oxigênio, bem como a disponibilidade de luz onde o sulfeto estará presente.

$\mathrm{Na}$ superfície da coluna de água, desenvolvem-se microrganismos fotossintetizantes e autotróficos, através da fotossíntese oxigênica (a molécula de água é o doador de elétrons, tendo como subproduto da fotossíntese o $\mathrm{O}_{2}$ ). Também na superfície pode desenvolver um biofilme constituído por bactérias aeróbias heterotróficas e uma mistura de metabólitos excretados ou sintetizado por elas, como por exemplo: lipídeos, proteínas e polissacarídeos.

Numa zona logo abaixo, bactérias fotoheterotróficas, obtêm energia a partir da luz solar e usam ácidos orgânicos como fonte de carbono para a síntese celular. Esses microrganismos crescem em condições anaeróbias, no entanto, não suportam elevadas concentrações de $\mathrm{H}_{2} \mathrm{~S}$.

$\mathrm{Na}$ zona oxigenada, além das bactérias fotossintéticas, poderão encontrar-se bactérias oxidantes de enxofre, que são quimiolitotróficos (obtêm energia a partir da oxidação do $\mathrm{H}_{2} \mathrm{~S}$ e sintetizam a matéria orgânica a partir do $\mathrm{CO}_{2}$ ).
No fundo da coluna, devido à presença da celulose, haverá um rápido consumo do oxigênio pelas bactérias heterotróficas, fazendo com que se tenha uma zona anaeróbica, desta forma, somente a superfície da coluna será oxigenada.

$\mathrm{Na}$ lama depositada no fundo da coluna, ocorrerão os processos fermentativos, onde as substâncias geradas servirão de substrato para as bactérias redutoras de sulfato (BRS's), favorecendo seu desenvolvimento. Essas bactérias, através de respiração anaeróbia, reduzem os íons sulfatos a sulfetos.

Os sulfetos gerados pelas BRS's servirão de substrato para bactérias anaeróbias fototróficas (BAF's), sulfobactérias de coloração verde e púrpura, que se desenvolverão de uma forma estratificada ao longo da coluna, de acordo com a gradiente de sulfeto. As BAF's obtêm energia a partir da fotossíntese anoxigênica (processo metabólico no qual as bactérias utilizam a luz para produzir ATP e produzem $\mathrm{NADPH}$ a partir da oxidação de $\mathrm{H}_{2} \mathrm{~S}$, que age como doador de elétrons, resultando na produção de enxofre elementar). O enxofre elementar produzido através da fotossíntese anoxigênica, precipita-se no sedimento no fundo da coluna, retornando à coluna d'água pela ação metabólica das BRS's. A Tabela 1 mostra os principais grupos bacterianos que possuem um papel principal na oxidação do enxofre. 
Tabela 1 - Relação dos Principais Grupos de Bactérias Oxidantes de Enxofre Encontradas na Coluna de Winogradsky

\begin{tabular}{|c|c|c|}
\hline GRUPO & GÊNERO & CARACTERÍSTICAS \\
\hline Gram negativa & Beggiatoa & $\begin{array}{l}\text { Bactériadeslizantelongaefilamentosa, nãofrutificante, quimiolitotrófica, } \\
\text { não fotossintética e aeróbica. Assemelha-se morfologicamente às } \\
\text { cianobactérias, porém não é fotossintética. Utiliza a oxidação do } \mathrm{H}_{2} \mathrm{~S} \\
\text { como fonte de energia, acumulando grânulos de enxofre no interior } \\
\text { de seu citoplasma, e utiliza o } \mathrm{CO}_{2} \text { como fonte de carbono. Bactéria } \\
\text { deslizante oxidante de enxofre. }\end{array}$ \\
\hline Gram negativa & Thiobacillus & $\begin{array}{l}\text { Bacilo quimiolitotrófico, não fotossintética e aeróbica. Obtêm } \\
\text { energia pela oxidação do sulfeto de hidrogênio ou enxofre elementar, } \\
\text { produzindo sulfato, e utiliza o } \mathrm{CO}_{2} \text { como fonte de carbono. Bactéria } \\
\text { incolor oxidante do enxofre. }\end{array}$ \\
\hline Gram negativa & Chromatium & $\begin{array}{l}\text { Coco ou bacilo, fotoautotrófica púrpura sulfurosa e anaeróbica. Possui } \\
\text { depósitos internos de enxofre. Obtêm energia por meio de reações } \\
\text { fotoquímicas e produz seus materiais celulares a partir do } \mathrm{CO}_{2} \text {. Sua } \\
\text { fotossíntese difere da fotossíntese das plantas por não gerar o oxigênio } \\
\text { durante o processo. (fotossíntese anoxigênica). Bactéria púrpura do } \\
\text { enxofre. }\end{array}$ \\
\hline Gram negativa & Chlorobium & $\begin{array}{l}\text { Bacilo curvado, sem motilidade, fotoautotrófica púrpura sulfurosa e } \\
\text { anaeróbica. Obtêm energia por meio de reações fotoquímicas e produz } \\
\text { seus materiais celulares a partir do } \mathrm{CO}_{2} \text {. Sua fotossíntese difere da } \\
\text { fotossíntese das plantas por não gerar o oxigênio durante o processo. } \\
\text { (fotossíntese anoxigênica). Bactéria verde do enxofre }\end{array}$ \\
\hline Gram positiva & Clostridium & $\begin{array}{l}\text { Bacilo, quimioheterotrófico, anaeróbico estrito, formador de endoesporo. } \\
\text { Os produtos de seu metabolismo fermentativo são utilizados como } \\
\text { substrato por outros grupos microbianos. Bacilo gram positivo formador } \\
\text { de endoesporo. }\end{array}$ \\
\hline Gram negativa & Desulfovibrio & $\begin{array}{l}\text { Vibrião. Anaeróbica obrigatória, utiliza as formas oxidadas do enxofre, } \\
\text { tais como sulfatos }\left(\mathrm{SO}_{4}{ }^{2-}\right) \text { ou enxofre elementar }\left(\mathrm{S}^{0}\right) \text { como aceptor final } \\
\text { de elétron. O produto desta reação é o sulfeto de hidrogênio. Bactéria } \\
\text { dissimilatória redutora do sulfato ou enxofre. }\end{array}$ \\
\hline
\end{tabular}

Adaptado de Rogan (2000).

\subsection{Metais pesados}

O termo metais pesados refere-se aos elementos e suas formas iônicas que pertencem ao grupo de transição e não transição da tabela periódica com densidade maior que $5 \mathrm{~g} . \mathrm{cm}^{-3}$ ou que possuem número atômico maior a 20 . Incluem nessa classificação os metais, semimetais e até não metais, como o Selênio. Esses elementos possuem a capacidade de acumularem nos tecidos vivos, pois os seres vivos não possuem a capacidade de excretá-los. Além do fato mencionado, esses metais ligam-se as enzimas, provocando sua inativação ou mesmo aumentando a atividade de algumas, resultando em alterações na sua função catalítica. Com isso, esse elemento vai se acumulando ao longo da cadeia alimentar numa proporção crescente e o consumidor do topo da cadeia terá sempre uma concentração maior de metal acumulado que indivíduos produtores.
Azevedo (2005) descreve que alguns metais como o cobre, ferro, manganês, níquel e zinco são essenciais para o desenvolvimento de todos os organismos vivos, porém, em pequena quantidade, em grande quantidade são tóxicos. Metais como o alumínio, cádmio, chumbo e mercúrio não possuem funções metabólicas e podem causar várias disfunções nos seres vivos. A contaminação ambiental por metais pesados ocorre, principalmente, por via antrópica, ou seja, através de resíduos industriais descartados sem tratamento.

\section{Objetivos}

\subsection{Objetivos gerais:}

O presente trabalho teve como objetivo a montagem de colunas de Winogradsky, utilizando as amostras de sedimento e de água coletadas em um manancial e contaminandoas com metais pesados. 


\subsection{Objetivos específicos:}

Observar o desenvolvimento das sulfobactérias em ambientes contaminados com metais pesados, de forma que possa ser avaliada a alteração da diversidade da microbiota presente na coluna de Winogradsky.

Verificar se os efeitos da contaminação por metais pesados nas colunas de Winogradsky podem ser observados sem a utilização de instrumentos ópticos, de forma que possa ser utilizada como demonstração didática em aulas práticas de Microbiologia Aplicada.

\section{Materiais e Métodos}

O projeto foi desenvolvido nos laboratórios multidisciplinares do Centro Universitário de Volta Redonda, UniFOA, e seguindo as seguintes etapas:

1. Escolha do local que fornecerá o sedimento e água para a montagem da coluna:

A amostra de sedimento e água para a confecção da coluna foi retirado no córrego Secades, bairro Conforto na cidade de Volta Redonda/RJ, localizada a $22^{\circ} 31^{\prime} 17,20^{\prime \prime}$ de latitude sul e $44^{\circ} 07^{\prime} 00,41^{\prime \prime}$ de longitude oeste. No momento da coleta, foi medido o $\mathrm{pH}$ do córrego, conforme o "Standard Methods for the Examination of Water and Wastewater" APHA (1998), de forma tal que se preparasse uma solução tampão que representasse o $\mathrm{pH}$ original do manancial, que neste caso foi 6,95 . Figuras 2 (A e B).

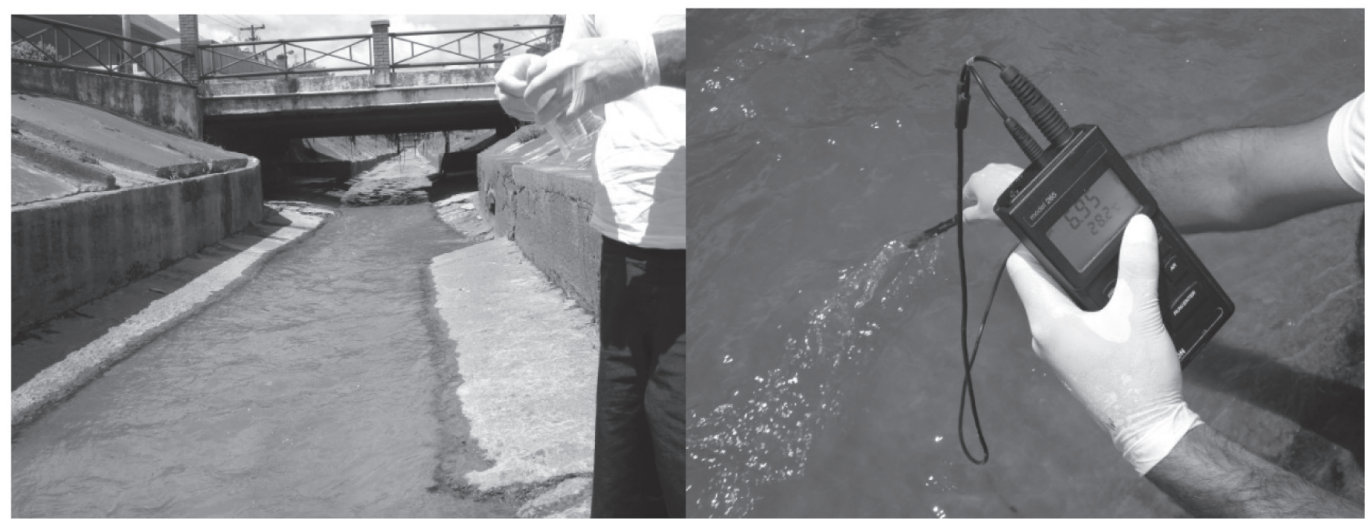

A - ponto de coleta da amostra

B - Medição do pH do córrego

Figura 2 - Coleta do lodo para confecção da coluna

2. Confecção das colunas de winogradsky com o material coletado:

A confecção das colunas de winogradsky seguiram as etapas, modificadas de Rogan (2000):

a. Misturar $100 \mathrm{~g}$ do sedimento fresco com a fonte de carbono orgânico (5 $\mathrm{g}$ de carboximetilcelulose - $\mathrm{CMC}$ ), e a fonte de carbono inorgânico $\left(2 \mathrm{~g} \mathrm{CaCO}_{3}\right)$. Como fonte de enxofre, $2 \mathrm{~g}$ de $\mathrm{CaSO}_{4}$. Essa mistura foi transferida para o interior da proveta, com o auxílio de uma espátula. Figura 3A. b. Adicionado 1 litro da água coletada no manancial (preservada em geladeira a $5^{\circ} \mathrm{C}$ ) cuidadosamente, de forma que houvesse o mínimo de perturbação na superfície do substrato.

c. Ajustado o pH da solução com solução tampão de Mcllvaine (fosfato dissódicoácido cítrico), pH 7,0 confeccionado segundo Morita (1993).

d. guardado um período de 24 horas para que os microrganismos presentes na água e remanescentes no lodo se restabeleçam e o sedimento decante. Figura 3. 


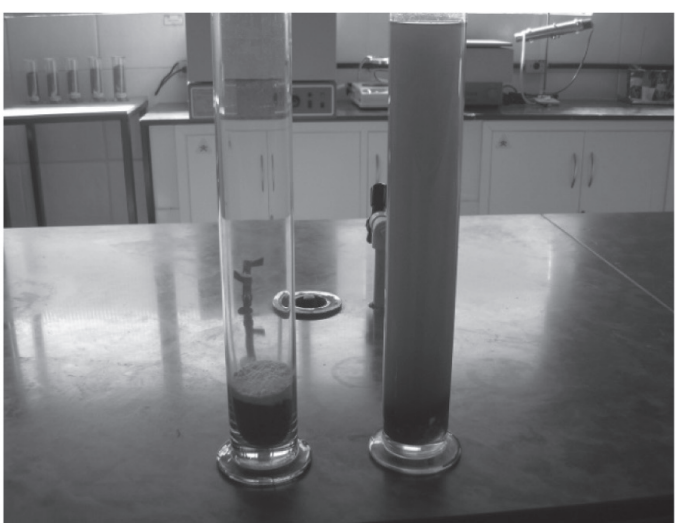

A - Colunas com o substrato para o desenvolvimento microbiano

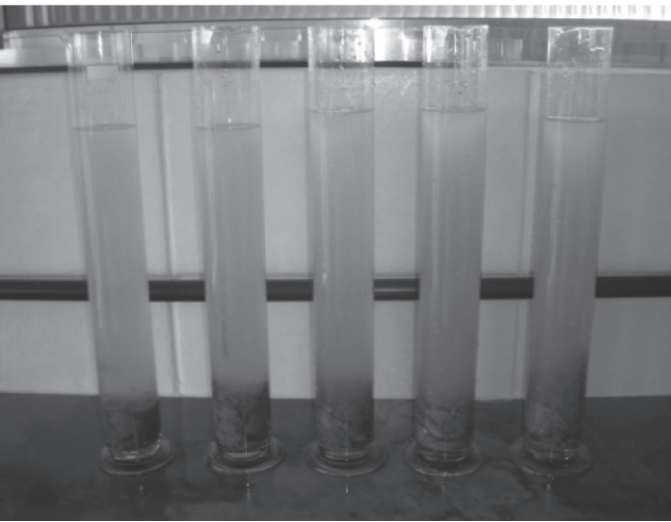

B - Colunas aguardando decantação

Figura 3 - Preparação das colunas

e. Identificada as colunas e feita a adição dos metais pesados, tendo como referência a portaria do Ministério do Meio Ambiente, CONAMA 357 de 2005, tendo como base o limite máximo de lançamento do metal como efluente. $\mathrm{O}$ valor adicionado à coluna foi uma concentração dez vezes (10x) a concentração máxima estabelecida na portaria. A concentração adicionada e o valor de referência encontram-se listados na Tabela 1, e deixando uma coluna como teste em branco, que será a referência do desenvolvimento microbiano no ambiente sem contaminação. Figura 4.

Tabela 1 - Forma de Adição do Contaminante nas Colunas de Winogradsky

\begin{tabular}{c|c|c|c|c|c}
\hline Coluna & Elemento & $\begin{array}{c}\text { Limite Máximo } \\
\text { Conama 357 }\end{array}$ & $\begin{array}{c}\text { Concentração a } \\
\text { ser Adicionada à } \\
\text { Coluna }\end{array}$ & Forma de Adição & $\begin{array}{c}\text { Quantidade } \\
\text { Adicionada à } \\
\text { Coluna }\end{array}$ \\
\hline 1 & - & - & - & - & - \\
\hline 2 & $\mathrm{Hg}$ & $0,01 \mathrm{mg} \cdot \mathrm{L}^{-1}$ & $0,10 \mathrm{mg} \cdot \mathrm{L}^{-1}$ & $\mathrm{HgCl}_{2}$ & $0,23 \mathrm{mg}$ \\
\hline 3 & $\mathrm{~Pb}$ & $0,50 \mathrm{mg} \cdot \mathrm{L}^{-1}$ & $5,00 \mathrm{mg} \cdot \mathrm{L}^{-1}$ & $\left(\mathrm{CH}_{3} \mathrm{COO}\right)_{2} \mathrm{~Pb} \cdot 3 \mathrm{H}_{2} \mathrm{O}$ & $9,15 \mathrm{mg}$ \\
\hline 4 & $\mathrm{Cd}$ & $0,20 \mathrm{mg} \cdot \mathrm{L}^{-1}$ & $2,00 \mathrm{mg} \cdot \mathrm{L}^{-1}$ & $\mathrm{CdSO}_{4} \cdot 8 / 3 \mathrm{H}_{2} \mathrm{O}$ & $4,56 \mathrm{mg}$ \\
\hline 5 & $\mathrm{Cr}$ & $0,50 \mathrm{mg} \cdot \mathrm{L}^{-1}$ & $5,00 \mathrm{mg} \cdot \mathrm{L}^{-1}$ & $\mathrm{~K}_{2} \mathrm{CrO}_{4}$ & $18,67 \mathrm{mg}$ \\
\hline
\end{tabular}

Os elementos contaminantes foram adicionados às colunas através da diluição dos respectivos sais em balões volumétricos e transferência utilizando pipetas volumétricas.

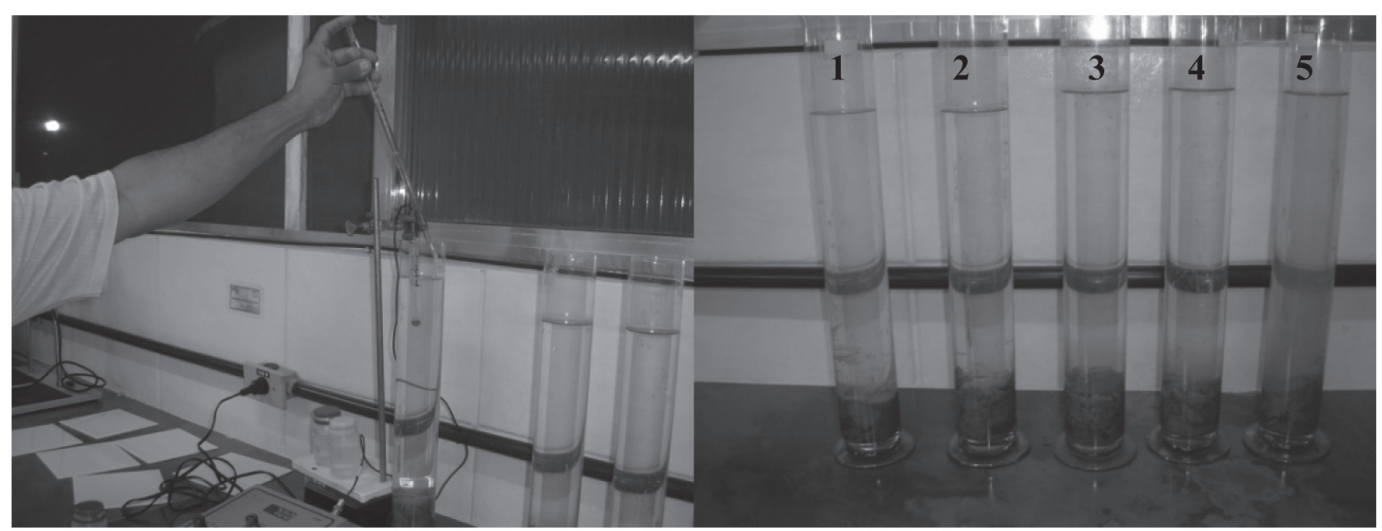

A - Adição do metal pesado e ajuste do $\mathrm{pH}$

$\mathrm{B}$ - Colunas com metal pesado adicionado:

1- branco; 2 - $\mathrm{Hg} ; 3$ - Pb; 4 - Cd; 5 - $\mathrm{Cr}^{6+}$ 
3. Desenvolvimento das colônias microbianas

Foi monitorado o desenvolvimento das colônias por um período de 60 dias e registra- do as alterações ocorridas nas cinco colunas, e comparando com a coluna que não recebeu a contaminação (branco). Figura 5.

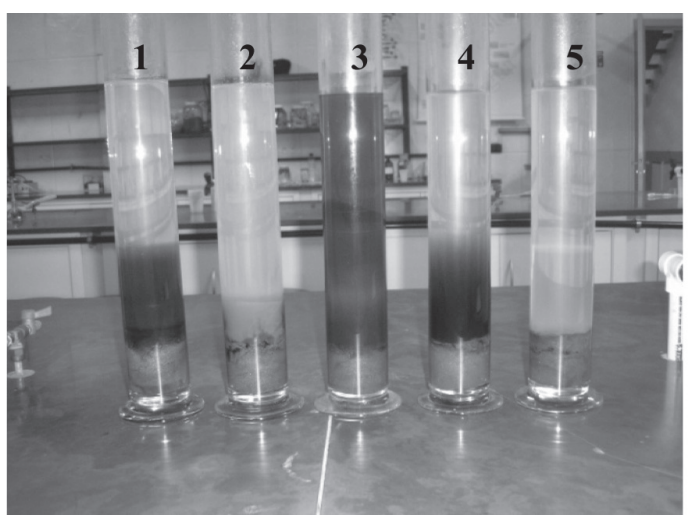

A - Colunas após 30 dias de inoculação dos metais pesados:

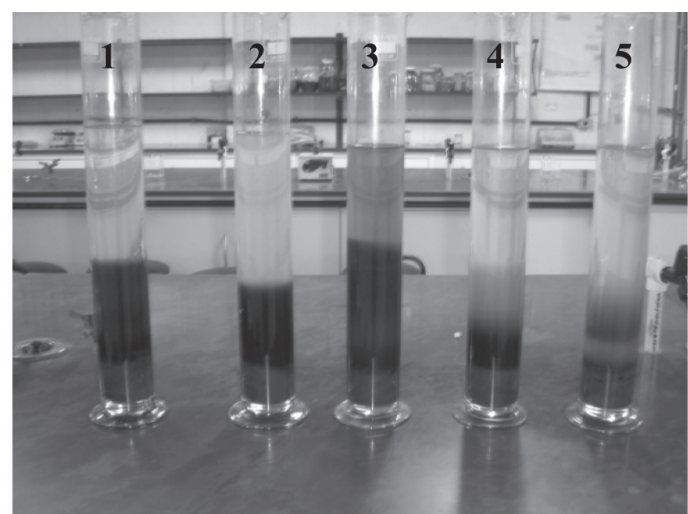

B - Colunas após 60 dias de inoculação dos metais pesados: 1- branco; $2-\mathrm{Hg} ; 3-\mathrm{Pb} ; 4-\mathrm{Cd} ; 5-\mathrm{Cr}^{6+}$

Figura 5 - Desenvolvimento microbiano nas colunas de Winogradsky

\section{Resultados e discussão}

Observou-se que nas colunas contaminadas com mercúrio e cromo VI, as bactérias que habitam o sedimento e a zona anaeróbia tiveram o desenvolvimento retardado em relação à coluna sem contaminação. Na coluna contaminada com chumbo, houve inibição de bactérias fotossintetizantes oxigênicas, evidenciado pelo desenvolvimento de bactérias sulforredutoras, devido à coloração negra formada ao longo da coluna, decorrente da precipitação de sulfetos metálicos, principalmente do sulfeto de ferro (FeS). A coluna contaminada com cádmio não apresentou alterações visíveis no desenvolvimento das colônias microbianas, quando comparado com a coluna sem contaminação, sugerindo que a concentração de cádmio adicionada não causou tanto impacto nos microrganismos presentes na coluna.

Nas primeiras semanas já se pode observar a estratificação das comunidades microbianas ao longo da coluna, de acordo com as condições ambientais que elas se encontravam, sendo que a coluna que apresentava contaminação com cromo foi a que mais demorou para o desenvolvimento das sulfobactérias.

\section{Conclusões}

Através das colunas de Winogradsky foi possível demonstrar a interdependência da diversidade microbiana presente num ecossistema e que a presença de determinados metais pesados na água afeta a sobrevivência e desenvolvimento desta comunidade.

A presença do metal pesado simulado na coluna contaminada causou uma perda de diversidade microbiológica, principalmente na coluna contaminada com o cromo, que apresentou uma considerável diminuição na produção de biomassa bacteriana, em comparação às outras colunas, o que leva a considerar o desequilíbrio ambiental que este elemento pode causar num corpo d'água, afetando principalmente as cadeias alimentares, pois impacta diretamente na base da cadeia.

A coluna de Winogradsky se mostra como um eficiente instrumento didático a ser adotado numa aula de microbiologia para um curso de engenharia ambiental, pois nele é possível formular infinitas variações de contaminantes onde se pode verificar virtualmente qualquer processo de desenvolvimento ou inibição de comunidades microbianas. 
1. APHA-AMERICANPUBLICHEALTH ASSOCIATION. Standard methods for examination of water and wastewater. 20 ed. Washington D.C., 1998, 1316p.

2. AZEVEDO, Ricardo A. and LEA, Peter J.. Preface: Toxic metals in plants. Braz. J. Plant Physiol. [online]. 2005, vol.17, n.1, pp. 1-1. ISSN 1677-0420.

3. CONSELHO NACIONAL DO MEIO AMBIENTE - CONAMA. 2005. Resolução Conama $\mathbf{n}^{\circ}$ 357. Disponível em: $<$ www.mma. conama.gov.br/conama $>$ Acesso em 24/04/2011.

4. FACULTAT DE CIÊNCIAS EXACTAS Y NATURALES - UBAEXACTAS (Argentina). Departamento de Química Biológica. Disponível em $<\mathrm{http}$ :/ www.qb.fcen.uba.ar/microinmuno/ SeminarioBiodiversidad.htm $>$. Acesso em 24/04/2011.

5. GRANT, W.D. y LONG, P.E. Microbiologia Ambiental. Zaragoza, Espanha: Acribia, 1989.

6. MORITA, T; ASSUMPÇÃO, R.M.V. Manual de Soluções, Reagentes e Solventes. Padronização, Preparação, Purificação. 2ª ed - São Paulo, Brasil: Edgard Blucher, 1993.

7. ROGAN, Brian. The Woodrow Wilson Foundation Leadership Program for Teachers. Disponível em: $<\mathrm{http}: /$ www.woodrow.org/teachers/bi/2000/ Winogradsky_Column/winogradsky_ column.html> . Acesso em 24/04/2011.
Endereço para Correspondência:

Anderson Gomes anderson.gomes@foa.org.br

Centro Universitário de Volta Redonda - UniFOA Av. Paulo Erlei Alves Abrantes, $n^{\circ} 1325$ Três Poços - Volta Redonda - RJ

CEP: $27.240-560$ 